\title{
Poems Syndrome Treated with Radiotherapy And A Literature Review
}

\author{
Daniele Candini and Eva Fernández Lizarbe* \\ Radiation Oncology Department, Ramóny Cajal University Hospital, Spain
}

Submission: April 03, 2017; Published: April 13, 2017

"Correspondence Address: Eva Fernández Lizarbe, Radiation Oncology Department, Ramóny Cajal University Hospital, Madrid, Spain, Tel: +34 651420822; Email: eva.lizarbe@gmail.com

Abstract

POEMS syndrome is a rare plasma cell disorder that causes a paraneoplastic syndrome. Main characteristics are peripheral neuropathy, monoclonal gammopathy, sclerotic bone lesions and Castleman disease. Many other important clinical features can be present to help the diagnosis such as organomegaly, oedema, ascites, papilledema, endocrinopathy, skin changes and thrombocytosis. POEMS syndrome is a systemic disease that in $30-40 \%$ of cases can be presented in a "localized" onset if there is no bone marrow infiltration by plasma cells and there are no more than three bone lesions. These patients are good candidates for local treatments, such as radiation therapy, with a satisfactory long-term response and better overall survival.

We report a case of a 24 year-old woman with POEMS syndrome who presented with insidious onset, progressive motor polyneuropathy, organomegaly and skin changes. Magnetic resonance of the pelvis showed an osteosclerotic lesion. Immunoelectrophoresis using the immunofixation method revealed lambda chain $(\lambda)$ monoclonal gammopathy. The patient was given radiotherapy in the bone lesion, with an excellent and quick response to the treatment. In this review we analysed the treatment outcomes and role of radiotherapy in a selected management of localized POEMS syndrome, also emphasizing the importance of a prompt diagnosis of a rare disease, which is shown to be treatment responsive in some cases.

Keywords: Castleman; Poems Syndrome; Polyneuropathy; Radiation Therapy

\section{Introduction}

POEMS syndrome is a rare paraneoplastic syndrome secondary to plasma-cell proliferative disorders. The acronym, coined by Bardwick in 1980 [1], refers to some, but not all, characteristics of the pathology: polyneuropathy, organomegaly, endocrinopathy, monoclonal gammopathy and skin changes. Three facts must be noted: there is no need for all five characteristics to be present in order to make a diagnosis; there are other important manifestations not contemplated in the acronym, such as: papilledema, extravascular volume overload, sclerotic bone lesions, thrombocytosis/erythrocytosis, high levels of VEGF (vascular endothelial growth factor), thrombophilia and pulmonary dysfunction in respiratory tests; there is a variation of POEMS syndrome, called Castleman's disease, that is not associated with monoclonal gammopathy.

POEMS syndrome is also known as osteosclerotic myeloma, Takatsuki's syndrome or Crow-Fukase's syndrome [2]. Initially, it was thought to be characteristic of the Japanese population. Lately, various cases were described also in France [3], China
[4], India [5] and United States [6]. A statistical analysis made in Japan in 2003 showed a prevalence of 0,3 for 100.000 people [2]. Pathogenesis is not well known [7], but there are multiple characteristics that can help in the differential diagnosis with multiple myeloma (MM): first, main symptoms are not usually bone pain, bone marrow infiltration by plasma cells or kidney dysfunction; instead of them neuropathy, endocrinological alterations, high levels of VEGF and extravascular volume overload are common. Second, sclerotic bone lesions are often found; overall survival is typically higher; and last, in $95 \%$ of the cases, the monoclonal protein detected is light chain lambda $(\lambda)$ type. We present a case report of a woman diagnosed with localized POEMS syndrome and treated with radiotherapy with excellent results.

\section{Case Report}

A 24 year-old woman, without pathological medical history, consulted at the Emergency Department for asthenia, 7-10 kg weight loss in a month and a half, night sweats and lower limbs 


\section{Cancer Therapy \& Oncology International Journal}

weakness with no autonomous walking. Physical examination showed several hypo pigmented skin lesions on face, thorax and left thigh, digital clubbing, in addition to mild hirsutism. On palpation, we also found small and hard but non-tender laterocervical, axillary and inguinal lymph nodes and non-tender mild hepatosplenomegaly. Neurological examination revealed bilateral papilledema, 2/5 strength in flexion of hips, 4/5 in flexion and extension of feet and knees. Patellar reflexes were abolished. Vibratory sensibility was abrogated in right ankle and paretic gait was noted.

Blood tests showed thrombocytosis (564.000 $\mu \mathrm{L})$ and lower levels of albumin $(2,9 \mathrm{~g} / \mathrm{dL})$.

The patient was hospitalized and additional tests were run, revealing the following findings:

a. Monoclonal paraproteinaemia: $\operatorname{IgG} \lambda$ monoclonal (570 mg/dL).

b. Lumbar puncture: high level of proteins $(310,14 \mathrm{mg} /$ dL).

c. Electromyography: Mixed motor polyneuropathy of demyelinating type, symmetrical and of proximal predominance in both legs.

d. Abdominal ultrasound: homogeneous splenomegaly $(140 \mathrm{~mm})$.

e. Body CT scan: hepatosplenomegaly and supra and infradiaphragmaticadenomegaly. Bone lesion of left ischium with malignant radiological characteristics and a soft tissue component.

f. Bone scintigraphy: intense and irregular increase of osteogenic reaction, with central cold area in left ischium.

g. Pelvic MRI: lytic lesion in left acetabular posterior wall, with aggressive characteristics; asymmetric denervation signs in various muscle groups of the pelvis; significant neuritis signs in both lumbo-sacral plexuses and right sciatic nerve (Figure 1).

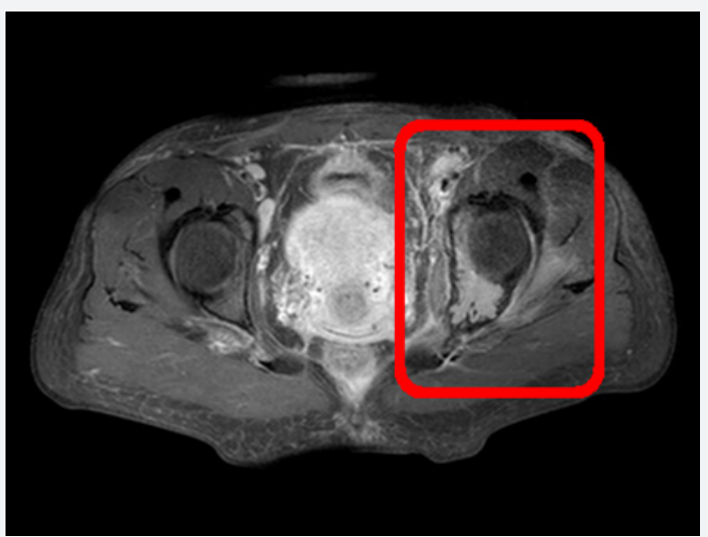

Figure 1: Pelvic MRI: Lytic lesion in left acetabular posterior wall. h. Spinal MRI: diffuse enhancement in cauda equina area (Figure 2).

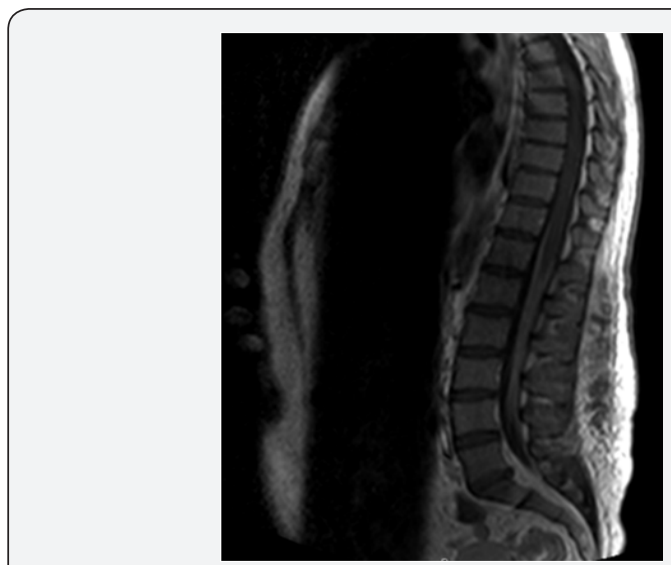

Figure 2: Spinal MRI: Contrast enhancement in the cauda equina.

i. Left inguinal lymph node biopsy: Reactive lymphadenitis with Castlemanoid/Castleman's disease findings (mixed variant, hyalinomuscular-plasmocellular).

j. Bone biopsy of left acetabular lesion: no pathological findings.

Table 1: Diagnostic criteria of the POEMS syndrome: Polyneuropathy, Organomegaly, Endocrinopathy, M protein, Skin (skin changes). POEMS criteria met by our patient are underlined $[7,8]$. aDue to the high prevalence of diabetes mellitus and thyroid abnormalities, these isolated diagnoses are not sufficient to validate this minor criterion.

\begin{tabular}{|c|c|}
\hline Defining features & $\begin{array}{c}\text { Polyneuropathy (typically } \\
\text { demyelinating) Monoclonal paraprotein } \\
\text { (in most cases } \lambda \text { ) }\end{array}$ \\
\hline Mayor features & $\begin{array}{c}\text { Castleman's disease Sclerotic bone } \\
\text { lesion/lesions High levels of VEGF }\end{array}$ \\
\hline \multirow{5}{*}{ Minor features } & $\begin{array}{c}\text { Organomegaly (hepatomegaly and/ } \\
\text { or splenomegaly and/or adenopaties) } \\
\text { Extravascular volume overload } \\
\text { (ascites, oedema, pleural effusion) } \\
\text { Endocrinopathy (adrenal, pituitary, } \\
\text { gonadic, parathyroidal, thyroidal } \\
\text { a and pancreatica) Skin changes } \\
\text { (hyperpigmentation, hypertrichosis, } \\
\text { haemangiomas, plethora, acrocianosis, } \\
\text { flushing, leukonychia) Papilledema } \\
\text { Thrombocytosis and/or polycythaemia }\end{array}$ \\
\hline \multirow{5}{*}{ Other signs and symptoms } & $\begin{array}{c}\text { Weight loss, nail clubbing, } \\
\text { hyperhidrosis, pulmonary } \\
\text { hypertension/restrictive pulmonary } \\
\text { disease, haemorrhagic diathesis, } \\
\text { diarrhoea, lower levels of vit } B_{12}\end{array}$ \\
\hline
\end{tabular}

Since the patient met POEMS syndrome criteria (Table 1), without bone marrow infiltration by plasma cells (Table 1), it was decided to start first-line treatment with 3D external radiotherapy (Figures $3 \& 4$ ) to the left ischium sclerotic bone lesion plus margin (total dose of $46 \mathrm{~Gy}, 2 \mathrm{~Gy} /$ day, with the Precise Elekta linear accelerator, with $6 \mathrm{MV}$ photon energy through 2 


\section{Cancer Therapy \& Oncology International Journal}

conformed anterior-posterior and postero-anterior beams). Tolerance to radiation treatment was good, with excellent response and a complete recovery of the strength in lower limbs after the third session. At the end of the whole treatment, the patient was able to walk and stand up from a chair without help.

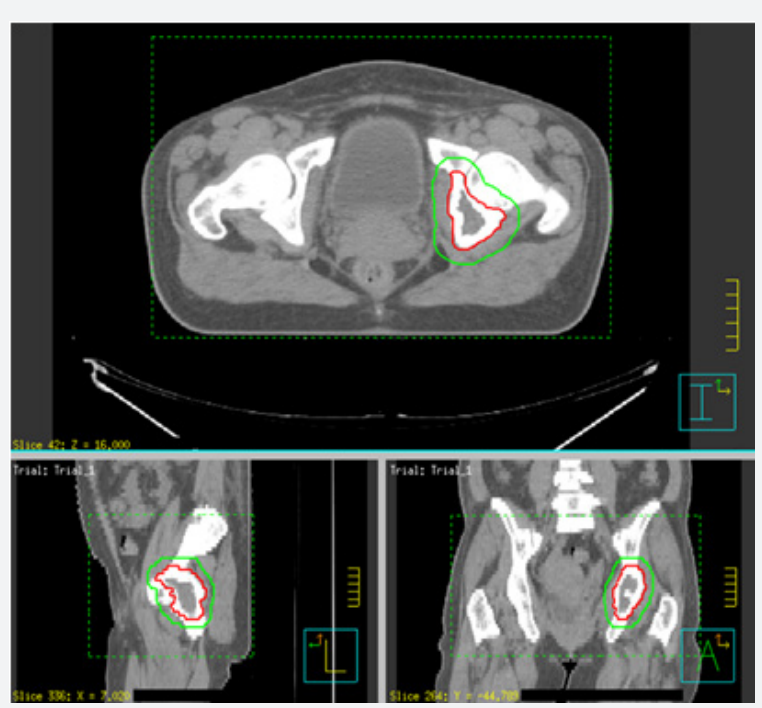

Figure 3: Radiation treatment countoring. Red line corresponds to the visible lytic lesion (Gross Tumor Volume, GTV). Green line is the treatment volume plus a margin of error (Planning Tumor Volume, PTV).

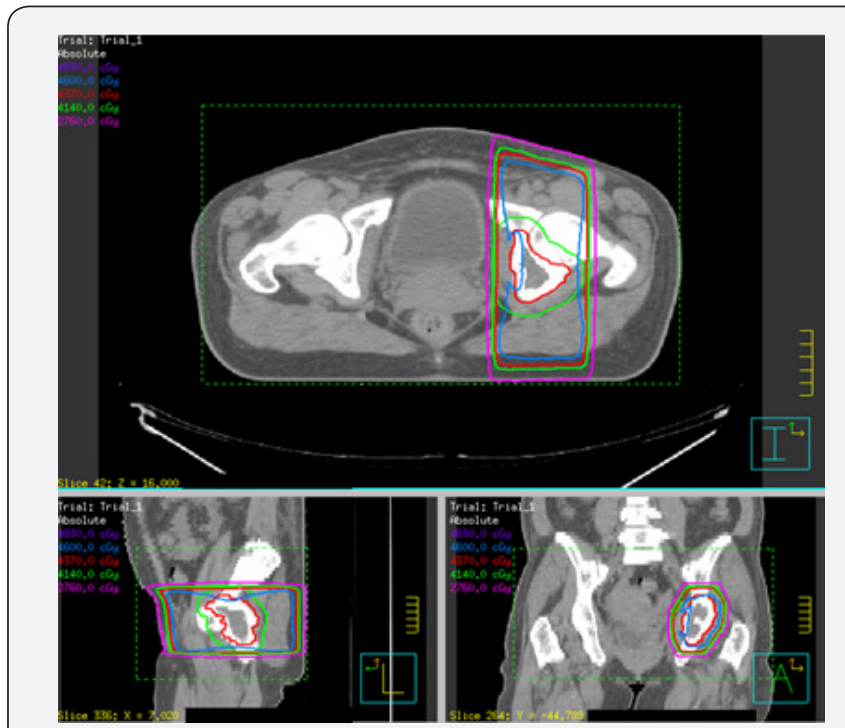

Figure 4: Radiation treatment planning with the isodoses of radiation (cGy). The blue line corresponds to the $100 \%$ of prescribed dose and the pink one to the $60 \%$.

A PET/CT scan performed 3 months after the treatment showed no pathological uptake of the radiotracer. Subsequential body CT scans and haematological determinations every 3 months showed no evidence of disease, and at present time the patient has reached 28 months with no relapse, and she is currently pregnant.

\section{Discussion}

The diagnosis of POEMS syndrome is often delayed because of its unusual symptoms, which usually point to a more frequent neurological disorder such as acute demyelinating inflammatorypolyneuropathy (Guillain-Barre syndrome). POEMS syndrome must be distinguished from POEMS/ Castleman's disease, which presents no monoclonal paraprotein and a very mild or absent peripheral neuropathy, but with other minor features of POEMS syndrome. Currently, diagnostic criteria from Mayo Clinic [8] are generally accepted and widely used. Diagnosis needs the presence of two defining features, one major feature and, at least, one minor feature (Table 1).

Not infrequently, in the differential diagnosis, it is necessary to take into account Castleman's disease (or giant follicular lymphoid hyperplasia), which is a rare lymphoproliferative disease, with different clinical presentations, from an asymptomatic unifocal mass (unicentric) to multifocal masses with multiple symptoms (multicentric). Symptoms can range from B-symptoms to several autoimmune phenomena or a POEMS syndrome. Many published cases of Castleman's disease are similar to cases of POEMS syndrome. Multicentric Castleman's disease with or without peripheral neuropathy tends to be different: patients with peripheral neuropathy are more likely to have oedema and peripheral circulation disorders, and more frequently present a $\lambda$ monoclonal protein in serum and/or urine. Between $11 \%$ and $30 \%$ of patients with POEMS syndrome who have a monoclonal peak, also present histological alterations characteristic of Castleman's disease in biopsies of adenopathy, such as angiofollicular hyperplasia, hyalinevascular variant in most cases.

Only patients with peripheral neuropathy and monoclonal gammopathy can be classified as POEMS syndrome. Without one of these two characteristics, patients are classified as POEMS variant/Castleman's disease if they present other characteristics of the POEMS syndrome. Castleman's disease often has intense polyclonal hypergammaglobulinaemia. Neuropathy in patients with Castleman's disease tends to be milder than that of patients with POEMS syndrome and is more frequently sensitive. However, in its evolution it will progress to demyelination and axonal degeneration with normal conduction, and an abnormal capillary proliferation, similar to that observed in the affected ganglia. Finally, in contrast to the POEMS syndrome, where the most consistently elevated cytokine is VEGF, in Castleman's disease the predominant cytokine is IL-6.

As the pathogenesis of POEMS syndrome is not well known, risk stratification is based on the clinical phenotype in preference to specific molecular markers. The number of criteria presented has no prognostic value, not including the absence of a monoclonal peak. Patients with a bone marrow biopsy of the iliac crest with no plasma cells infiltration (as far as $25 \%$ of the cases in the published series) have a better outcome and are candidates for treatment with radiotherapy [8-12]. Patients with 


\section{Cancer Therapy \& Oncology International Journal}

up to 3 isolated bone lesions have also been candidates for local treatments, with radiotherapy being the initial and potentially definitive therapy for these patients [13]. In this article, 38 patients $(26 \%$ of the total) were given targeted radiation as their initial primary therapy with a 4-year overall survival rate of $97 \%$ and, despite the fact that nearly $40 \%$ of this cohort had more than 1 bone lesion, rates of progression and overall survival were excellent without any difference in risk of relapse in patients with 1 or 3 lesions.

It has been also shown that radiotherapy in these patients improves overall survival [7]: between 1998 and 2002, 99 patients were identified and analysed. Median overall survival was 165 months but the subgroup of the patients who received radiation therapy $(n=64)$ had superior survival compared to those patients with no radiation treatment (68\% vs $40 \%$ at 150 months; $\mathrm{p}<0.04$ ). This data were confirmed in a later publication of the same group [14] where a risk-adapted therapy was planned: for those patients with a dominant sclerotic lesion, first line therapy was irradiation; on the contrary, patients with diffuse sclerotic lesions or disseminated bone marrow involvement and for those who had progression of their disease 3 to 6 months after completing radiation therapy received systemic therapy.

In a Mayo clinic's series of 35 patients [15] with localized POEMS syndrome, external radiotherapy (median dose 45 Gy in 25 fractions, range 35-54 Gy) was used as primary treatment with the results of a significant symptomatic control (regarding peripheral neuropathy, anasarca, organomegaly, papilledema, skin changes, monoclonal peak and VEGF levels). In 50-70\% of patients another 4 different response parameters were evaluated: decrease in VEGF values, changes in avidity of uptake in PET-CT scans with 18F-FDG, haematological response and clinical response, documented respectively in the $14 \%, 22 \%$, $31 \%$ and $47 \%$ of the cases. There are no published data on longterm follow-up (more than 4 years) but there are the data on time to relapse: in the Mayo Clinic series, more than half of the failures occurred in the first 12 months after treatment with radiotherapy, with a progression-free survival rate of $52 \%$ at 4 years. What is not clear in this retrospective series is whether these were true relapses or were guided by patient and physician anxiety due to poor response. Another limitation the small number of patients $(\mathrm{n}=35)$ and the lack of an uniform criterion used to decide if and when rescue therapy was appropriate. However, in a sub-analysis of this series, two baseline predictors of treatment failure were identified: reduced carbon monoxide diffusion capacity $(<75 \%)$ and an increased level of total urinary protein ( $\geq 0.093 \mathrm{~g}$ in 24 hours) [16].

Although approximately half of the patients required additional therapies, radiotherapy is a simple and effective option for a subset of patients with localized disease. Patients with a greater extent of disease or with disseminated monoclonal peak are candidates for systemic therapy, even though radiotherapy may play a role in this category of patients as well: in a Korean study, six patients with multiple lesions were submitted to radiation treatment, and it was found that these patients effectively improved the symptoms associated with the POEMS syndrome (such as ascites or pleural or pericardial effusion), despite the haematological response to radiotherapy being relatively poor, and concluding that radiotherapy may be effective as a palliative treatment to improve clinical symptoms in patients with POEMS syndrome with multiple bone lesions or in his systemic form [17].

An update of the Mayo Clinic's experience to 2016 [18] was recently published with the inclusion of 291 patients treated between 1974 and 2014. The authors summarize that patients diagnosed after 2003 have a greater number of POEMS syndrome characteristics at diagnosis, possibly due to a more careful baseline assessment. Another significant finding of this study is the increase in frequency in the practice of autologous blood stem cell transplantation, due to the good safety and longterm efficacy data of this technique. The authors confirm the very good long-term results of patients with POEMS syndrome, with 10-years overall survival of $62 \%$ and an even better result for patients treated after 2003: 79\%, emphasizing that patients treated with radiation therapy as first line treatment reached better and stable responses. Authors conclude that, for the first time, new prognostic risk factors were found in the POEMS syndrome: albumin levels at diagnosis $>3.2 \mathrm{~g} / \mathrm{dL}$ and reaching a complete haematological response are considered positive prognostic factors.

\section{Conclusion}

Despite various limitations, these published results and our case report shows how radiotherapy is an easy and effective treatment for a subgroup of patients with POEMS syndrome, with good results in symptomatic control and short-medium time response. However, the population of patients that benefit from radiotherapy is still poorly understood and we are in need of further investigation in order to identify clinical or laboratory biomarkers that could point to a subset of patients where radiotherapy is most effective.

\section{References}

1. Bardwick PA, Zvaifler NJ, Gill GN, Newman D, Greenway GD, et al. (1980) Plasma cell dyscrasia with polyneuropathy, organomegaly, endocrinopathy, M protein, and skin changes: the POEMS syndrome. Report on two cases and a review of the literature. Medicine 59(4): 311-322.

2. Nakanishi T, Sobue I, Toyokura Y, Nishitani H, Kuroiwa Y, et al. (1984) The Crow-Fukase syndrome: A study of 102 cases in Japan. Neurology 34(6): 712-720.

3. Soubrier MJ, Dubost JJ, Sauvezie BJ (1994) POEMS syndrome: A study of 25 cases and a review of the literature. French study group on POEMS syndrome. Am J Med 97(6): 543-553.

4. Li J, Zhou DB, Huang Z, Jiao L, Duan MH, et al. (2011) Clinical characteristics and long-term outcome of patients with POEMS syndrome in China. Ann Hematol 90(70: 819-826. 


\section{Cancer Therapy \& Oncology International Journal}

5. Singh D, Wadhwa J, Kumar L, Raina V, Agarwal A, et al. (2003) POEMS syndrome: Experience with fourteen cases- Leuk Lymphoma 44(10): $1749-1752$

6. Dispenzieri A (2007) POEMS syndrome. Blood Rev 21(6): 285-299.

7. Dispenzieri A, Kyle RA, Lacy MQ Rajkumar SV, Therneau TM, et al. (2003) POEMS syndrome: Definitions and long-term outcomes. Blood 101(7): 2496-2506.

8. Ghandi GY, Basu R, Dispenzieri, Basu A, Montori VM, et al. (2007) Endocrinopathy in POEMS syndrome: The Mayo clinic experience. Mayo Clin Proc 82(7): 836-842.

9. Gaba AR, Stein RS, Sweet DL, Variakojis D (1978) Multicentric giant lymph node hyperplasia. Am J Clin Patho 69(1): 86-90.

10. Feigert JM, Sweet DL, Coleman M, Variakojis D, Wisch N, et al. (1990) Multicentricangiofollicular lymph node hyperplasia with peripheral neuropathy, pseudotumorcerebri, IgA dysproteinaemia, and thrombocytosis in women. A distinct syndrome. Ann Intern Med 113(5): 362-367.

11. Anonymous. Case records of the Massachusetts General Hospital. Weekly clinicopathological exercises. Case 10-1987. A 59-yearold woman with progressive polyneuropathy and monoclonal gammopathy. N Engl J Med 316: 606-618.
12. Hineman VL, Phyliky RL, Banks PM (1982) Angiofollicular lymph node hyperplasia and peripheral neuropathy: Association with monoclonal gammopathy. Mayo Clin Proc 57(6): 379-382.

13. Humeniuk MS, Gertz MA, Lacy MQ Kyle RA, Witzig TE, et al. (2013) Outcomes of patients with POEMS syndrome treated initially with radiation. Blood 122(1): 66-73.

14. Dispenzieri A (2011) POEMS syndrome: 2011 update on diagnosis, risk-stratification, and management. Am J Hematol 86(7): 591-601.

15. Dispenzieri A (2014) POEMS syndrome: 2014 update on diagnosis, risk-stratification, and management. Am J Hematol 89(2): 213-223.

16. Warsame R, Gertz MA, Lacy MQ, Kyle RA, Buadi F, et al. (2012) Trends and outcomes of modern staging of solitary plasmocytoma of bone. Am J Hematol 87(7): 647-651.

17. Dispenzieri A (2015) POEMS Syndrome: update on diagnosis, riskstratification, and management. Am J Hematol 90: 952-962.

18. Kourelis TV, Buadi FK, Kumar SK, Gertz MA, Lacy MQ, et al. (2016) Long-term outcome of patients with POEMS syndrome: An update of the Mayo Clinic experience. Am J Hematol 91(6): 585-589.

\section{Your next submission with Juniper Publishers} will reach you the below assets

- Quality Editorial service

- Swift Peer Review

- Reprints availability

- E-prints Service

- Manuscript Podcast for convenient understanding

- Global attainment for your research

- Manuscript accessibility in different formats

( Pdf, E-pub, Full Text, Audio)

- Unceasing customer service

Track the below URL for one-step submission https://juniperpublishers.com/online-submission.php 